\title{
Body size, habitat quality, and territory defense in Bachman's sparrow
}

\author{
Joseph M. Niederhauser*, Morgan C. Slevin, Erik G. Noonburg and \\ Rindy C. Anderson \\ Department of Biological Sciences, Florida Atlantic University, Davie, FL 33314, USA \\ *Corresponding author's e-mail address: jniederhause2015@fau.edu
}

Received 22 July 2020; initial decision 8 December 2020; revised 1 February 2021; accepted 22 February 2021; published online 12 March 2021

\begin{abstract}
Many wild populations of animals conform to the ideal despotic distribution (IDD) in which more competitive individuals exclude less competitive individuals from high quality resources. Body size and aggressiveness are two important traits for resource defense, and they positively covary so that larger individuals are usually more aggressive. Using Bachman's sparrows, we tested the hypothesis that larger birds are more aggressive and are thus able to compete for the best quality territories. We found that larger males were more aggressive, and more aggressive birds fledged at least one young. However, we did not find consistent relationships between aggressiveness and habitat characteristics. Our results suggest that Bachman's sparrows meet most of the predictions of the IDD. Frequent ecological disturbances, such as fires, might disrupt the IDD or make it difficult to detect. Additional studies are needed to test for relationships between ecological disturbances and territorial behaviour.
\end{abstract}

Keywords

aggressiveness, Bachman's sparrow, body size, habitat quality, ideal despotic distribution.

\section{Introduction}

The ideal free distribution (IFD; Orians, 1969; Fretwell \& Lucas, 1970; Fretwell, 1972) explains how animals should distribute themselves in environments with patchy distributions of resources (food, mates, nesting habitat). Individuals are assumed to have equal competitive ability, to have complete information about the availability of resources, and are free to enter or leave any patch of their choice (no resource defense). Patch quality decreases 
as exploiter density increases, and individuals select the most profitable patch relative to the number of existing competitors in the patch. It follows that high quality habitats contain more resources and attract a higher density of competitors. Many wild populations do not meet the assumptions of the IFD and do not conform to its predictions (reviewed in Kennedy \& Gray, 1993; Tregenza, 1995). In particular, individuals typically vary in their competitive ability, and resources are often defended to the exclusion of others.

An alternative to the ideal free distribution is the ideal despotic distribution (IDD; Fretwell, 1972), which predicts that competitive differences will cause individuals to be asymmetrically distributed among resources (Fretwell, 1972). Dominant individuals secure territories in the highest quality habitats often guarding more resources than needed, hence the name 'despot', and subordinates are forced to defend lower quality territories or are excluded from suitable habitat to become non-breeding floaters (Kokko $\&$ Sutherland, 1998). Most breeding systems in which individuals defend territories are assumed to follow the IDD, however, many violate some or all of the assumptions and predictions underlying this model (Abrahams, 1986; Pagán et al., 2009). In order to meet the requirements of the IDD, there must be variation in both competitiveness and habitat quality.

Body size and aggressiveness are traits that confer competitive advantage in resource defense (Maynard Smith \& Brown, 1986). Larger individuals are often more aggressive, are more likely to win contests, and more often secure the best and most abundant resources (reviewed in Huntingford, 2013). Aggressiveness also confers an advantage in securing resources, and more aggressive individuals often win and defend the best territories. For example young brown trout (Salmo trutta; Johnsson et al., 2000), redbacked salamanders (Plethodon cinereus; Gabor \& Jaeger, 1995), and little bustards (Tetrax tetrax; Morales et al., 2014) were more aggressive defending higher quality territories than lower qualities territories. Aggressiveness might relate positively with territory quality because more aggressive individuals have greater resource holding potential and tend to secure the best territories, or because individuals on high quality territories value them more and fight harder to keep them (Beletsky \& Orians, 1987). If aggressiveness positively relates to territory quality, then more aggressive individuals may be spatially clustered together in patches of high quality habitat (Duckworth, 2006; Scales et al., 2013). 
In songbirds, there is mixed support for the positive relationship between body size and aggressiveness. In great tits (Parus major; Garnett, 1981) and Capricorn silvereyes (Zosterops lateralis; Robinson-Wolrath \& Owens, 2003), larger individuals won more fights than smaller individuals. By contrast, body size and aggressiveness are unrelated in other species (e.g., redcollared widowbirds, Euplectes ardens; Pryke et al., 2001) or may differ by sex (e.g., American redstarts, Setophaga ruticilla; Marra, 2000).

The relationship between aggressiveness and habitat quality in songbirds is also mixed. Male song sparrows (Melospiza melodia) defending territories that historically produced greater clutch sizes are more aggressive (Scales et al., 2013), and males defending territories in urban areas and with more supplemental food, which may be perceived as better quality habitat, are more aggressive than males in rural areas and territories without supplemental food (Foltz et al., 2015). In the American redstart, high quality territories are defended by more aggressive males than low quality territories (Marra, 2000). In contrast, female superb fairy-wrens (Malurus cyaneus) are more aggressive in low quality habitats compared to high quality habitats (Cain \& Langmore, 2016), possibly due to a 'desperado effect' (Grafen, 1987), in which individuals are willing to escalate conflicts because the alternative is no reproduction and possibly death.

In this study, we ask how body size, aggressiveness, and territory quality are related in a south Florida population of Bachman's sparrow ( $\mathrm{Peu}$ caea aestivalis). Specifically, we examined whether the best territories are defended by larger, more aggressive males as predicted by the IDD. Finally, we tested for spatial clustering of aggressive males as predicted if the males with the largest resource holding potential (larger, more aggressive) dominate territories in areas of the highest habitat quality.

Bachman's sparrows are passerine songbirds that reside in the southeastern United States (Dunning et al., 2018). Previous work has shown individual variation in aggressiveness in the context of territory defense (Ali \& Anderson, 2018), but aggressiveness has not been compared to variation in morphological traits or to habitat variables. Throughout their range, Bachman's sparrows reside in open-pine woodlands dominated by slash (Pinus elliottii), longleaf (Pinus palustris), and loblolly (Pinus taeda) pines that are maintained by prescribed fire application (Dunning et al., 2018). At our study site, parcels of slash pine are burned during the growing season every two years in a mosaic pattern creating a patchwork of areas that were burned recently, 
one year ago, and two years ago. Therefore we predicted variation in habitat quality due to differential stages of succession following prescribed burns, and we expected this habitat heterogeneity would translate into variation in territory quality based on characteristics that confer greater densities for this species (Tucker et al., 2004). However, recently burned areas do not have greater nest success (Tucker et al., 2006; Winiarski et al., 2017a) but still have better breeding productivity (Tucker et al., 2006), leaving questions about what constitutes a high-quality territory for Bachman's sparrows. In addition, we predicted that the most competitive males should obtain the best quality territories and should therefore show spatial clumping: localized areas of high quality habitat should consist of territories defended by more aggressive males (Duckworth, 2006; Scales et al., 2013). Finally, if Bachman's sparrows follow the IDD based on competitive ability, then body size and aggressiveness should co-vary positively (Maynard Smith \& Brown, 1986).

\section{Materials and methods}

\subsection{Study site and species}

We measured aggressiveness and territorial characteristics of male Bachman's sparrows at Jonathan Dickinson State Park (hereafter JDSP; $27^{\circ} 00^{\prime} \mathrm{N}$, $80^{\circ} 07^{\prime} \mathrm{W}$ ). Our study area was a 600 ha section of slash pine flatwood within the 4600 ha state park. Slash pine habitat is managed at JDSP by conducting prescribed fires by burn units (mean $52.08 \pm 8.60$ ha, range 6.88-144.03) during the growing season (April-September) every two years. Our study subjects were adult males each captured with mist nets and given a unique combination of one US Geological Survey numbered metal band and three color bands. Males were captured or recaptured from 5 March to 10 May 2018 at least a month before aggressiveness and territorial characteristics were measured. We measured body mass using a digital scale (AWS-600, American Weigh Scales, Cumming, GA, USA), wing chord length using a wing rule, and tarsus length using callipers. Additionally, we marked the capture site with GPS. We were unable to age birds at capture by plumage, but we were able to determine territory tenure based on relocating birds over multiple years. We measured current reproductive success of each male by using a modified Vickery Reproductive Index (Vickery et al., 1992; Winiarski et al., 2017b) from repeated observations (mean $8.36 \pm 0.37$ 
observations, range: 4-13) throughout the breeding season. These observations took place in the morning between 0700 and 1200 and were at least 1 h. We compiled observational data into 4 seasonal productivity metrics spanning the entire breeding season. We defined a male as unpaired if no female was seen with the male throughout the season, paired if a female was seen with him for $>4$ weeks but no evidence of nesting, paired and nesting if we saw some evidence that the pair was building a nest or feeding nestlings, and fledged young if at least one fledgling was seen with the male. Females were identified by their behaviour around the focal males regardless of whether they were banded. If an individual remained in close proximity $(<5 \mathrm{~m})$ to the male for most of the observation period without resulting in an aggressive encounter, then we assumed that it was a female.

\subsection{Aggressiveness}

We measured aggressiveness for 41 males from 20 April to 5 July 2018. Aggressiveness was measured by performing simulated territorial intrusions ('playbacks') following the general methods of Nowicki et al. (2002) and Hyman et al. (2004). Each playback consisted of a 6-min playback recording. We made 40 unique stimuli using the songs of 30 different males to avoid pseudoreplication (Kroodsma et al., 2001). Each playback stimulus contained a total of 72 songs which consisted of three different sequences of two primary songs (six song types total per stimuli), one whisper song, and one warble song (see Ali \& Anderson, 2018 for descriptions of song categories) with each song repeated twice and the whole 36 song sequence repeated twice. We included whisper and warble songs in playback stimuli because both song categories are produced in aggressive contexts in this species (Ali \& Anderson, 2018). Each song exemplar was followed by 1-3 s of silence to produce one song every $5 \mathrm{~s}$, a song rate found during aggressive contexts in this species (Ziadi, 2019). All stimuli were calibrated to peak amplitude of $85 \mathrm{~dB}$ SPL at $1 \mathrm{~m}$, measured with a sound level meter (A-weighting; 732A, B\&K Precision, Yorba Linda, CA, USA). All stimuli were made using Syrinx 2.6 (J.M. Burt, Syrinx, Seattle, WA, USA) and Audacity 2.1.2 software (The Audacity Team, available online at http://www.audacityteam.org). Aside from the length of the playbacks, we followed the same playback procedure as Ali and Anderson (2018): before playback began we located a subject male on his territory. We did not quantify pre-playback behaviour because subjects were typically on the ground and concealed under vegetation and thus their behaviour could not be observed consistently. We placed 
a plastic, hand-painted replica of a male Bachman's sparrow (three different replicas were used) in a perched posture on a tree stump or branch with an audio speaker (IFS03, iFox Creations, Portland, OR, USA) concealed underneath the model by a piece of thin brown fabric. We placed the model and speaker within $15 \mathrm{~m}$ of a preferred singing perch that was greater than $30 \mathrm{~m}$ away from territorial borders. At the end of the playback period we concealed the replica by pulling a string attached to it so that it fell from its perch into the vegetation below.

During playback trials one observer (JN or RA) stood $\geqslant 16 \mathrm{~m}$ away from the replica/speaker and narrated into a digital recorder (Tascam DR-100mkII) the bird's proximity to the replica and all instances of songs and other behaviours. Following Peters et al. (1980) the male's proximity was estimated using markers at 2, 4, 8 and $16 \mathrm{~m}$ on either side of the replica. Trials were later scored for the bird's proximity during each 5-s period: subjects in the 0-2 $\mathrm{m}$ range were scored as $1 \mathrm{~m}$ from replica, the 2-4 $\mathrm{m}$ range as $3 \mathrm{~m}$, the $4-8 \mathrm{~m}$ range as $6 \mathrm{~m}$, the $8-16 \mathrm{~m}$ range as $12 \mathrm{~m}$, and the greater than $16 \mathrm{~m}$ as $24 \mathrm{~m}$ (Peters et al.,1980; Ali \& Anderson, 2018). Proximity was averaged and songs and behaviours were summed over the playback period. Songs were categorized as 'broadcast', 'whisper', or 'warble' by ear. 'Flights' were scored any time the male flew $>2 \mathrm{~m}$. 'Fly-bys' were scored when the male flew very close to the model nearly touching it. 'Attacks' were scored if the male made physical contact with the model either by flying into or landing on it.

\subsection{Territory measurements}

We measured habitat characteristics on the territories of 31 Bachman's sparrows from 24 May to 1 August 2018. We measured vegetation characteristics shown to influence occupancy in this species (Tucker et al., 2004; Winiarski et al., 2017b). Territory size was determined by marking singing perches with GPS points (mean $15.97 \pm 0.69$ points, range 10-27) over multiple days throughout the breeding season, and then territories were mapped using minimum convex polygons in ArcMap (v. 10.6; ESRI, Redlands, CA, USA) (Delany et al., 1995). Bachman's sparrow territories at JDSP are contiguous or nearly contiguous, so we were able to calculate territory density (hereafter 'density') for each male's territory as the number of males, including the focal male and his adjacent neighbours, divided by the total area of those males' territories. We did not consider males to be adjacent neighbours if 
they were separated by habitat features like rivers or thick forest. Time since fire was determined for territories using the number of days between the date that we measured the habitat variables and the date that the territory was last burned. We collected a multitude of vegetation measures for each territory following the methods of Winiarski et al. (2017b). We sampled five random points within each territory that each had $2,10-\mathrm{m}$ transects following the cardinal directions and subsampled every $2 \mathrm{~m}$ along each transect $(0,2,4,6$, 8 , and $10 \mathrm{~m}$ ) and the point at the transect centre $(5 \mathrm{~m})$, for a total of $13 \mathrm{sub}-$ samples per transect. At each subsample, we counted the number of times grass, shrub, and forb touched a Wiens pole ('hits') at 10-cm intervals from 0 to $200 \mathrm{~cm}$ along the pole's height, noted the maximum heights for each of those categories, and documented the dominant ground cover type as either vegetation, litter, or bare ground. We estimated tree density at each of the 5 random points by measuring basal area using a convex glass (Winiarski et al., 2017b). Unlike Bachman's sparrows in northern latitudes, seasonal ponds and wetlands make up a large portion of Bachman's sparrow habitat at JDSP, so we calculated wetland cover of territories in ArcMap 10.6.1 (ESRI, 2011) by drawing polygons of the wetland areas and measuring the area in hectares.

\subsection{Statistical analyses}

We used principal components analysis (PCA) to create principal components for body size and aggressiveness. For body size, we combined mass and the lengths for tarsus and wing into the size components. We kept the first principal component (Body size PC) because it was the only component with an eigenvalue greater than one and explained $53 \%$ of the variation in the data (Table A1 in the Appendix). Only one male attacked the replica in our study, so we quantified other variables as estimates of aggressiveness. We combined counts of flights, fly-bys, whisper songs, and the subject's average proximity to the replica/speaker because these four variables predict attack in Bachman's sparrow (Ali \& Anderson, 2018). We retained the first principal component (Aggressiveness PC; eigenvalue $>1$ ), which explained $46 \%$ of the variation in the data (Table A2 in the Appendix).

We used linear models (LMs) to compare the aggressiveness PC to body size measurements and territorial characteristics. We used one-way ANOVAs with Tukey's honest significant differences to assess the influence of reproductive index (1, unpaired; 2 , paired but no nesting; 3 , paired and nesting; 4, fledged young; Winiarski et al., 2017b) and territory tenure (how many years 
as a territory holder at JDSP) on the aggressiveness PC. We also built generalized linear models (GLMs) and LMs to make univariate comparisons of the number of flights, fly-bys, whisper songs, and proximity to the model to body size measurements (Table A5 in the Appendix), reproductive index, and territory tenure. Seasonality can affect testosterone and territoriality (Wingfield et al., 1987) as well as vegetation growth (Badeck et al., 2004), so Julian date is often included as a covariate in analyses that use those variables. Julian date did not have an effect on overall aggressiveness in a previous study on Bachman's sparrows (Ali \& Anderson, 2018) or in this study ( $t=1.674$, $p=0.102, N=41$ ), so it was not included in our aggressiveness analyses. The only vegetation characteristics that changed over Julian date were grass maximum height $(t=-2.850, p=0.008, N=31)$, vegetation cover $(t=-3.907, p<0.001, N=31)$, and litter cover $(t=4.323, p<0.001$, $N=31$ ), so we included Julian date when using those variables in analyses. Given the multiple variables used to describe territory characteristics, we ranked the importance of the LMs that compared the aggressiveness PC and territory characteristics using Akaike's information criterion for small sample sizes $\left(\mathrm{AIC}_{\mathrm{c}}\right.$ : Burnham \& Anderson, 2002). We considered models with $\Delta \mathrm{AIC}_{\mathrm{c}}<2$ to have the most support, values between 2 and 7 to have partial support, and values greater than 10 to have no support. We verified the best models by observing the model weights $\left(\omega_{i}\right)$, which explain the amount of residual variation in the data (Burnham \& Anderson, 2002).

We examined the spatial distribution of aggressiveness for the 41 males for which we measured aggressiveness by using a linear model to compare density to the aggressiveness $\mathrm{PC}$ and calculating spatial autocorrelation using R packages spdep (Bivand et al., 2013; Bivand \& Wong, 2018) and $n c f$ (Bjornstad, 2020). First, we calculated Moran's I for global spatial autocorrelation. Moran's $I$ describes the spatial concentration or dispersion for a measured variable across the entire subject area (Scott \& Janikas, 2010). We then tested the distribution for local spatial clustering using the Getis-Ord Gi* statistic (Getis \& Ord, 1992) and Anselin's local indicators of spatial autocorrelation (LISA; Anselin, 1995). The Gi* and LISA allow for a finer scale analysis of spatial patterns or local clusters that may not be detected in a global analysis.

Because of the high variation in some of our variables (see Tables A3 and A4 in the Appendix) and some patterns were not statistically significant, we adjusted our levels of significance. We considered significant trends with $p$ 


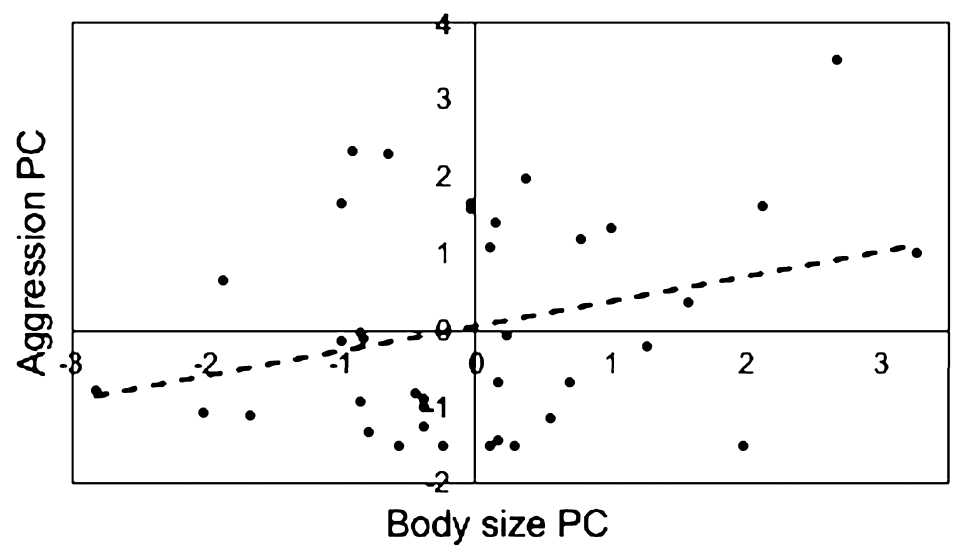

Figure 1. The relationship between aggressiveness principal component and body size principal component in male Bachman's sparrows at Jonathan Dickinson State Park in 2018. Positive body size and aggressiveness values indicate larger and more aggressive individuals, respectively.

values $<0.05, p$ values between 0.05 and 0.1 as non-significant trends, and values $>0.1$ as not significant. All statistical analyses were done in $\mathrm{R}$ 3.5.2 (R Core Team, 2013).

\section{Results}

\subsection{Body size and aggressiveness}

Male Bachman's sparrows varied in body size (Table A3 in the Appendix) and aggressiveness (Table A4 in the Appendix), and larger males were more aggressive. The aggressiveness PC tended to relate positively with body size ( $t=1.842, p=0.074, N=38$; Figure 1$)$ and many of the individual measures of aggressiveness (flights, fly-bys, whisper songs) and body size positively related to one another (Table A5 in the Appendix).

The aggressiveness PC trended toward a significant relationship with reproductive index $\left(F_{3,37}=2.778, p=0.055, N=41\right)$. Males that fledged at least one young were more aggressive overall than unpaired males (Reproductive index 4-1: $1.413 \pm 0.502, p=0.038$; Figure 2), and they made more fly-bys (Reproductive index 4-1: $z=1.365, p<0.001$ ) and whisper songs (Reproductive index 4-1: $z=8.792, p<0.001$ ). Additionally, males that fledged at least one young tended to spend more years as a territory holder $(\chi=11.777, p=0.067, N=41)$. 


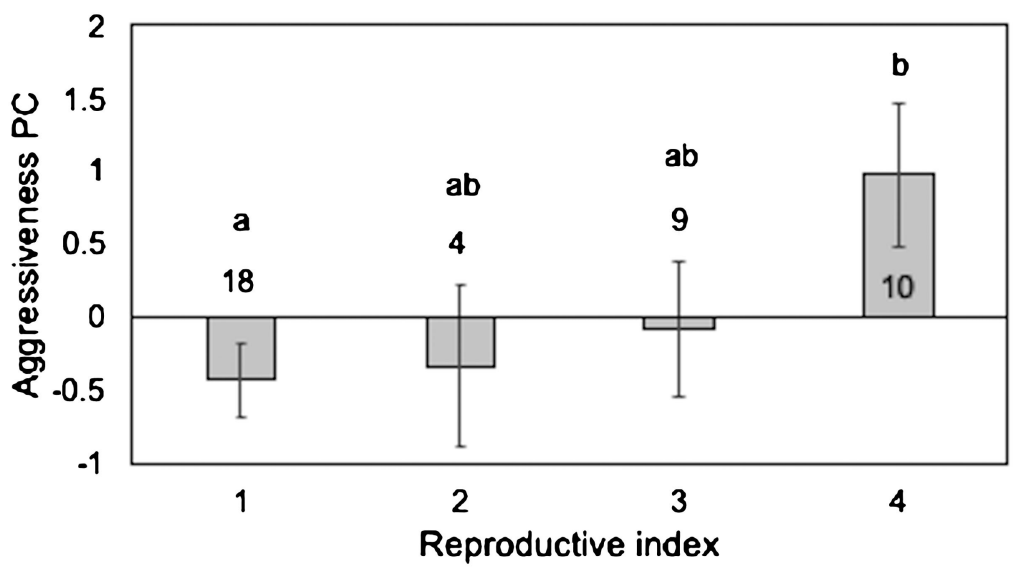

Figure 2. The mean \pm SE effect of reproductive index on the aggressiveness principal component in male Bachman's sparrows at Jonathan Dickinson State Park in 2018. 1, Unpaired; 2, paired but no nesting; 3, paired and nesting but no fledglings; 4, fledged young (Winiarski et al., 2017b). Positive aggressiveness values indicate more aggressive individuals. Letters above the bars show the results of Tukey's honest significant difference post hoc test: bars that do not share the same letters are significantly different $(p<0.05)$.

\subsection{Territory characteristics and aggressiveness}

Bachman's sparrow territories varied in their characteristics (Table A6 in the Appendix), but no territory characteristics were related to a male's reproductive index. However, density was related to some territorial characteristics. Densities were greater in territories that were recently burned $(r=0.636, p=<0.001, N=31)$, that had more bare ground $(r=0.371$, $p=0.040, N=31$ ), and tended to have less grass and forbs (Grass ground cover density: $r=-0.336, p=0.064, N=31$; Forb ground cover density: $r=-0.303, p=0.097, N=31)$.

Many vegetation characteristics related to overall aggressiveness, but most characteristics explained very little of the variation in aggressiveness (Table 1). The null model was the best model for explaining overall aggressiveness, but many models had substantial or partial support. The best models including vegetation characteristics included forb maximum height, pine basal area, time since fire, shrub ground cover density, percent litter cover, and forb ground cover density. Cumulatively the models explained only half the variation in aggressiveness $\left(\sum \omega_{i}=0.51\right)$.

The evidence for a spatial distribution of aggressiveness was mixed based on density and spatial autocorrelation. Males were more aggressive in greater 
Table 1.

Linear models examining the relationships between the aggressiveness principal component and vegetation characteristics of Bachman's sparrow territories $(N=31)$ at Jonathan Dickinson State Park in 2018.

\begin{tabular}{lcccc}
\hline Model & $k$ & $\mathrm{AIC}_{\mathrm{c}}$ & $\Delta \mathrm{AIC}_{\mathrm{c}}$ & $\omega_{i}$ \\
\hline Null & 1 & 111.731 & 0.000 & 0.162 \\
Forb maximum height & 2 & 111.873 & 0.142 & 0.151 \\
Pine basal area & 2 & 112.627 & 0.896 & 0.104 \\
Time since fire & 2 & 113.540 & 1.808 & 0.066 \\
Shrub ground cover density & 2 & 113.627 & 1.895 & 0.063 \\
Percent litter cover & 2 & 113.632 & 1.901 & 0.063 \\
Forb ground cover density & 2 & 113.704 & 1.973 & 0.061 \\
Percent vegetation cover & 2 & 113.802 & 2.071 & 0.058 \\
Grass ground cover density & 2 & 113.814 & 2.082 & 0.057 \\
Percent wetland cover & 2 & 113.872 & 2.140 & 0.056 \\
Percent bare cover & 2 & 113.936 & 2.204 & 0.054 \\
Grass maximum height & 2 & 113.936 & 2.204 & 0.054 \\
Shrub maximum height & 2 & 113.997 & 2.265 & 0.052 \\
\hline
\end{tabular}

Models were compared using Akaike's information criterion corrected for small sample size $\left(\mathrm{AIC}_{\mathrm{c}}\right)$.

densities ( $t=2.779, p=0.008, N=41$; Figure 3$)$. In contrast, global autocorrelation for the aggressiveness principal component was random ( $I=0.027, Z=0.748, p=0.455$; Figure A1 in the Appendix), and the local spatial clustering using the Getis-Ord Gi* statistic and Anselin's LISA revealed three significant clusters (Figure 4).

\section{Discussion}

We tested several predictions of the IDD in Bachman's sparrow, a seasonally territorial songbird. First, we predicted variation in competitiveness among individuals as measured by body size and aggressiveness. We found support for both predictions; both body size and aggressiveness varied among males (Tables A3 and A4 in the Appendix), and larger males were more aggressive than smaller males (Figure 1). Together, these data support the prediction of the IDD for variation in competitiveness in male Bachman's sparrows.

A second prediction of the IDD is that dominant (more competitive) individuals will secure high quality territories, and subordinates will be left with low quality territories. We found that Bachman's sparrow territories varied in their characteristics (Table A6 in the Appendix), but the characteristics we 


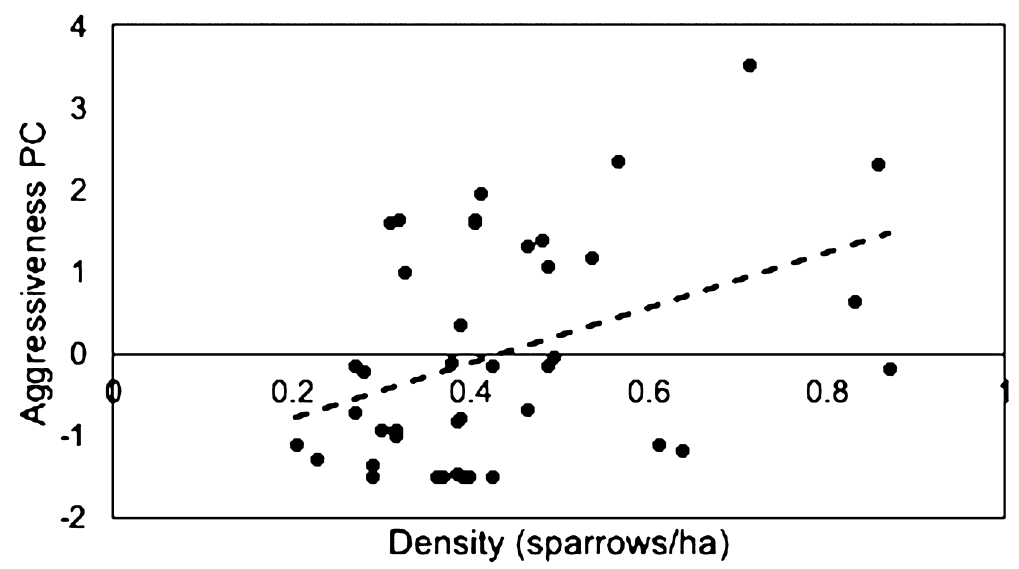

Figure 3. The relationship of sparrow density on the aggressiveness principal component for male Bachman's sparrows at Jonathan Dickinson State Park in 2018. Positive aggressiveness values indicate more aggressive individuals.

measured did not predict aggressiveness or reproductive success. Males were more aggressive in territories that produced young (Figure 2), consistent with the idea that better territories are more likely to fledge young. Overall, our data do not reveal whether variation in aggressiveness is due to the motiva-

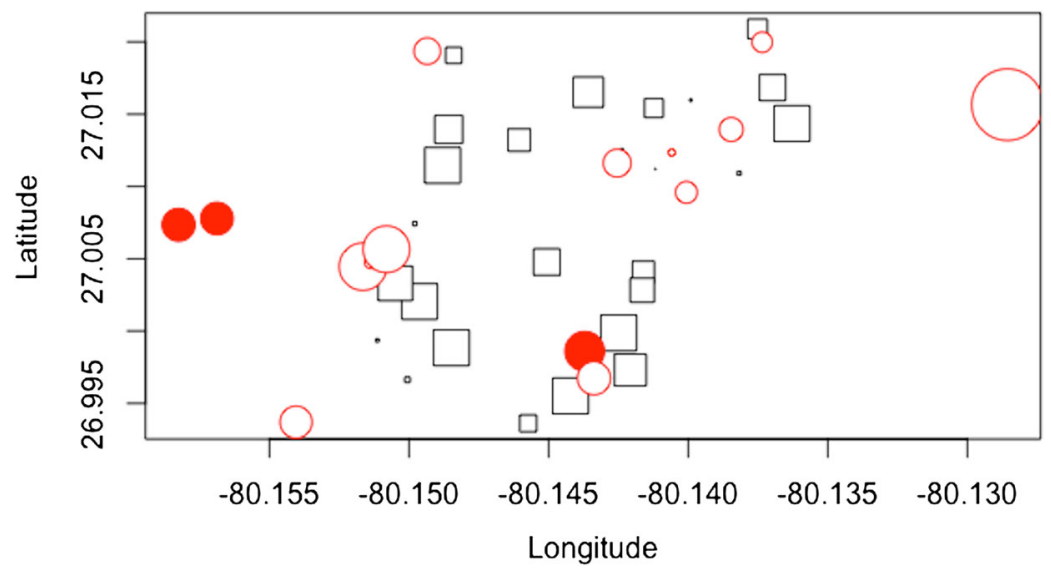

Figure 4. Anselin's local indicators of spatial autocorrelation (LISA) for the aggressiveness principal component with respect to longitude and latitude for male Bachman's sparrows at Jonathan Dickinson State Park in 2018. Red circles denote positive deviations from the mean, black squares denote negative deviations from the mean, and filled points are significant local correlations $(p<0.05)$. 
tion to defend a given territory (aspects of territory quality measured here or not), or due to qualities inherent to the male (body size), or due to a combination of both.

We measured vegetation characteristics that are important predictors of occupancy for other populations of this species (Winiarski et al., 2017b). These characteristics did not relate to producing young in our study, suggesting that we missed variables that are important for reproductive success in our population. Different vegetation characteristics may be selected at different stages of the Bachman's sparrow life cycle. For example, low woody shrubs are important microhabitat for nesting (Jones et al., 2013; Winiarski et al., 2017a) and escape cover (Winiarski et al., 2017b), but too much woody shrub from lack of fire leads to low bird densities and territory abandonment (Tucker et al., 2004; Brooks \& Stouffer, 2010; Taillie et al., 2015). Nestsites are often located in areas with bare ground and little grass (Jones et al., 2013; Winiarski et al., 2017a), but grass seed is a necessary component of Bachman's sparrow's adult diet (Wolf, 1977) and grass is used to build nests (Haggerty, 1995). Some of the territory characteristics did correlate with aggressiveness however, so they could be related to territory quality by conferring a competitive advantage or disadvantage during territorial disputes. For example, males were more aggressive in more recently burned territories, and recently burned habitats attract greater densities of sparrows, suggesting that burns create attractive habitat (this study; Tucker et al., 2004). We found no habitat variables that related to producing young, but it is possible that the increased aggressiveness we measured in more recently burned territories was related to the future reproductive success these birds will experience once vegetation succession leads to optimal habitat, similar to the increased aggression over cavities between mountain (Sialia currucoides) and western (S. mexicana) bluebirds in post-fire habitat (Duckworth, 2014). An alternative hypothesis is that the aggressive responses to playbacks may be more of a result of the social environment rather than the quality of the habitat. Greater densities could lead to increased aggressiveness (Figure 3) because of more territorial interactions between males in general ( $\mathrm{Li}$ et al., 2007; Knell, 2009; Manenti et al., 2015) or more specifically between territory owners and floaters (López-Sepulcre \& Kokko, 2005), which is what our playbacks simulate, but increased aggressiveness could also be the result of the assemblage of aggressive individuals present in those areas. Some examples of this include two naturally inbred strains of Drosophila melanogaster 
where aggressiveness at high densities depends on the relative abundance of the other strain (Kilgour et al., 2020) and blue-black grassquits (Volatinia jacarina) that are more aggressive in groups of only males than in groups that contain females, who are less aggressive, regardless of the group size (Lacava et al., 2011). Thus, increased aggressiveness of Bachman's sparrows in higher densities may be attributed to greater assemblages of more aggressive individuals rather than just greater assemblages of individuals in higher quality habitats.

Finally, the spatial distribution of males partially supported the predicted positive relationship between aggressiveness and habitat quality. Clustering of aggressive males is predicted by the IDD because the most competitive males should dominate the best quality territories, which should be clustered together in regions of high quality (Duckworth, 2006; Scales et al., 2013). We found only a few clusters of highly aggressive males (Figure 4), despite the positive relationship between density and aggressiveness. There are at least three explanations for this result. First, we may not have had sufficient samples sizes to determine the spatial distribution of these sparrows based on habitat quality or aggressiveness. However, Hyman et al. (2004) found significant clustering with only 26 song sparrows, suggesting that our sample size of 41 was probably sufficient. Although there may be differences in the life histories of song sparrows and Bachman's sparrows, this is the only study we are aware of that linked aggressiveness with habitat quality and spatial clustering. Second, because our study site is managed with prescribed burns to conserve fire-dependent species such as the Bachman's sparrow, the site might be dominated by relatively high quality habitat. If habitat quality varies little across our study site then we would not expect clustering, or our spatial scale may have been insufficient to identify clusters of quality habitat (Doligez et al., 2008). A related idea is that the habitat qualities most important to Bachman's sparrow nesting success are not clustered across the landscape in this managed habitat, and so most territories are of sufficient quality. A third explanation for the lack of clustering and the lack of a strong relationship between aggressiveness and territory characteristics is that male Bachman's sparrows at JDSP often defend the same territories for multiple seasons, even when they are burned (Niederhauser and Anderson, unpublished data). This may be because only portions of territories are burned (fires are low-intensity and burn patchily) leaving enough suitable habitat to survive and possibly reproduce. This idea aligns with a study of 
Bachman's sparrows in southern Georgia where most males did not leave their territories after a burn (Cox \& Jones, 2007). It appears that these sparrows will only abandon their territories if the entire area is burned (Seaman $\&$ Krementz, 2000). We hypothesize that male Bachman's sparrows choose a territory and attempt to retain it for multiple seasons rather than moving around to dominate the highest quality patches each year, as predicted by the IDD. Given the natural history of this species, selection may be favouring birds that invest in a territory over a longer time because a mediocre territory may become a good one in the following year if there is fire. Bachman's sparrow habitats are managed by conducting controlled burns every 2 years (Tucker et al., 2004), so presumably individual territories fluctuate cyclically in quality. This hypothesis could be tested in a future study by manipulating territories with different fire intervals to test whether there is a quality threshold at which individuals abandon their territory to attempt to secure a better one.

Another caveat of our study is that we measured body size, aggressiveness, and habitat quality once for each male. A major issue in behavioural ecology research is measuring characteristics only once that are often plastic or measured with error (Niemelä \& Dingemanse, 2018a). Measuring these characteristics once may under- or overestimate the relationships between intrinsic states (i.e., body size) and personality traits (i.e. aggressiveness) when there is only a weak association between them (Niemelä \& Dingemanse, 2018b). In our study, it is possible we have overestimated the relationship between body size and aggressiveness and at the same time weakened the link between those variables and territory quality. To test this idea, we would need to repeat this study over multiple years to determine if our observed relationships hold.

In summary, Bachman's sparrows satisfy most of the predictions of the IDD. There is variation in both body size and aggressiveness, and larger males are more aggressive. We identified variation in some territorial characteristics and found evidence that aggressiveness relates to some aspects of territory quality, such as reproductive success and the amount of time since last burn. We found little evidence supporting the prediction that more aggressive males should be spatially clustered in areas of highest habitat quality, but we did find that males were more aggressive in areas with greater densities of sparrows. In some species there is evidence supporting most, if not all, of the predictions of the IDD, for example in wild 
and laboratory-raised trout (Oncorhynchus masou ishikawae, Hakoyama \& Iguchi, 2001; Salvelinus fontinalis, Purchase \& Hutchings, 2008), sideblotched lizards (Uta stansburiana; Calsbeek \& Sinervo, 2002), yellowlegged gulls (Larus michahellis; Oro, 2008), white-footed mice (Peromyscus leucopus; Halama \& Dueser,1994), red squirrels (Sciurus vulgaris; Wauters et al., 2008), and chimpanzees (Pan troglodytes; Murray et al., 2007). In other species, however, there is mixed support, for example in the Atlantic salmon (Salmo salar) a small-scale experiment found evidence for the IDD (Gotceitas \& Godin, 1992), but a large-scale experiment contradicted that support (Maclean et al., 2005). Some studies assume all predictions are met by demonstrating space-use dominance, but show no competitive advantage to explain that dominance (Andrén, 1990; Møller, 1991; Ens et al., 1995).

Overall, the IDD is thought to be a general phenomenon with predictions that are harder to test in some systems than in others. An intriguing possibility is that the prevalence of frequent ecological disturbances, such as floods or fires, influences the evolution of plasticity in traits related to resource defense, and this plasticity disrupts the IDD or makes it difficult to detect. Both phenotypic (Hendry et al., 2008) and behavioural plasticity (Tuomainen \& Candolin, 2011; Wong \& Candolin, 2015) are common in disturbed or fluctuating environments, so it would not be surprising for traits associated with the IDD, like aggressiveness, to be plastic in these environments. Future studies are needed to test this hypothesis, including longitudinal studies that track flexibility in individual traits related to resource defense, such as aggressiveness.

\section{Acknowledgements}

We would like to thank Paula Ziadi and Brin Cerbone for help conducting aggressiveness assays, and the Florida State Park Service for logistical support at Jonathan Dickinson State Park. This work was supported by a Memorial Grant from the Eastern Bird Banding Association and the Internal Grants Program from the Florida Atlantic University College of Science Initiative to Stimulate Extramural Funding. All procedures described here were approved by the Florida Atlantic University Institutional Animal Care and Use Committee (protocol No. A16-01). We also thank two anonymous reviewers whose suggestions improved the manuscript. 


\section{References}

Abrahams, M.V. (1986). Patch choice under perceptual constraints: a cause for departures from an ideal free distribution. - Behav. Ecol. Sociobiol. 19: 409-415.

Ali, S. \& Anderson, R. (2018). Song and aggressive signaling in Bachman's sparrow. - Auk 135: 521-533.

Andrén, H. (1990). Despotic distribution, unequal reproductive success, and population regulation in the jay Garrulus glandarius L. - Ecology 71: 1796-1803.

Anselin, L. (1995). Local Indicators of Spatial Association-LISA. - Geogr. Anal. 27: 93-115.

Badeck, F.W., Bondeau, A., Böttcher, K., Doktor, D., Lucht, W., Schaber, J. \& Sitch, S. (2004). Responses of spring phenology to climate change. - New Phytol. 162: 295-309.

Beletsky, L.D. \& Orians, G.H. (1987). Territoriality among male red-winged blackbirds II. Removal experiments and site dominance. — Behav. Ecol. Sociobiol. 20: 339-349.

Bivand, R.S. \& Wong, D.W.S. (2018). Comparing implementations of global and local indicators of spatial association. - Test 27: 716-748.

Bivand, R.S., Pebesma, E. \& Gómez-Rubio, V. (2013). Applied spatial data analysis with R, 2nd edn. - Springer, Berlin.

Bjornstad, O.N. (2020). ncf: spatial covariance functions. - R Packag. version 1.2-9. R Foundation for Statistical Computing, Vienna.

Brooks, M.E. \& Stouffer, P.C. (2010). Effects of hurricane Katrina and salvage logging on Bachman's sparrow. - Condor 112: 744-753.

Burnham, K.P. \& Anderson, D.R. (2002). Model selection and multimodel inference, 2nd edn. - Springer, New York, NY.

Cain, K.E. \& Langmore, N.E. (2016). Female song and aggression show contrasting relationships to reproductive success when habitat quality differs. - Behav. Ecol. Sociobiol. 70: 1867-1877.

Calsbeek, R. \& Sinervo, B. (2002). An experimental test of the ideal despotic distribution. J. Anim. Ecol. 71: 513-523.

Cox, J.A. \& Jones, C.D. (2007). Home range and survival characteristics of male Bachman's sparrows in an old-growth forest managed with breeding season burns. - J. Field Ornithol. 78: 263-269.

Delany, M.F., Moore, C.T. \& Progulske, D.R. (1995). Territory size and movements of Florida grasshopper sparrows. - J. Field Ornithol. 66: 305-309.

Doligez, B., Berthouly, A., Doligez, D., Tanner, M., Saladin, V., Bonfils, D. \& Richner, H. (2008). Spatial scale of local breeding habitat quality and adjustment of breeding decisions. - Ecology 89: 1436-1444.

Duckworth, R.A. (2006). Aggressive behaviour affects selection on morphology by influencing settlement patterns in a passerine bird. — Proc. Roy. Soc. Lond. B: Biol. Sci. 273: 1789-1795.

Duckworth, R.A. (2014). Human-induced changes in the dynamics of species coexistence: an example with two sister species. - In: Avian urban ecology: behavioural and physiological adaptations (Gil, D. \& Brumm, H., eds). Oxford University Press, New York, NY, p. 181-191. 
Dunning, J.B., Pyle, P. \& Patten, M.A. (2018). Bachman's sparrow (Peucaea aestivalis). In: Birds of North America, version 3 (Rodewald, P.G., ed.). Cornell Lab of Ornithology, Ithaca, NY.

Ens, B.J., Weissing, F.J. \& Drent, R.H. (1995). The despotic distribution and deferred maturity: two sides of the same coin. - Am. Nat. 146: 625-650.

ESRI (2011). ArcGIS desktop: release 10. — Environmental Systems Research Institute, Redlands, CA.

Foltz, S.L., Ross, A.E., Laing, B.T., Rock, R.P., Battle, K.E. \& Moore, I.T. (2015). Get off my lawn: increased aggression in urban song sparrows is related to resource availability. — Behav. Ecol. 26: 1548-1557.

Fretwell, S.D. (1972). Populations in seasonal environments. — Princeton University Press, Princeton, NJ.

Fretwell, S.D. \& Lucas, H.L. (1970). On territorial behavior and other factors influencing habitat distribution in birds-I. Theoretical development. — Acta Biotheor. 19: 16-36.

Gabor, C.R. \& Jaeger, R.G. (1995). Resource quality affects the agonistic behaviour of territorial salamanders. - Anim. Behav. 49: 71-79.

Garnett, M.C. (1981). Body size, its heritability and influence on juvenile survival among great tits, Parus major. - Ibis 123: 31-41.

Getis, A. \& Ord, J.K. (1992). The analysis of spatial association by use of distance statistics. — Geogr. Anal. 24: 189-206.

Gotceitas, V. \& Godin, J.G.J. (1992). Effects of location of food delivery and social status on foraging-site selection by juvenile Atlantic salmon. — Environ. Biol. Fish. 35: 291-300.

Grafen, A. (1987). The logic of divisively asymmetric contests: respect for ownership and the desperado effect. - Anim. Behav. 35: 462-467.

Haggerty, T.M. (1995). Nest-site selection, nest design and nest-entrance orientation in Bachman's sparrow. - Southwest. Nat. 40: 62-67.

Hakoyama, H. \& Iguchi, K. (2001). Transition from a random to an ideal free to an ideal despotic distribution: the effect of individual difference in growth. — J. Ethol. 19: 129137.

Halama, K.J. \& Dueser, R.D. (1994). Of mice and habitats: tests for density-dependent habitat selection. - Oikos 69: 107.

Hendry, A.P., Farrugia, T.J. \& Kinnison, M.T. (2008). Human influences on rates of phenotypic change in wild animal populations. - Mol. Ecol. 17: 20-29.

Huntingford, F.A. (2013). Animal conflict. — Springer, Berlin.

Hyman, J., Hughes, M., Searcy, W.A. \& Nowicki, S. (2004). Individual variation in the strength of territory defense in male song sparrows: correlates of age, territory tenure, and neighbor aggressiveness. - Behaviour 141: 15-27.

Johnsson, J.I., Carlsson, M. \& Sundstrom, L.F. (2000). Habitat preference increases territorial defence in brown trout (Salmo trutta). - Behav. Ecol. Sociobiol. 48: 373-377.

Jones, C.D., Cox, J.A., Toriani-Moura, E. \& Cooper, R.J. (2013). Nest-site characteristics of Bachman's sparrows and their relationship to plant succession following prescribed burns. — Wilson J. Ornithol. 125: 293-300. 
Kennedy, M. \& Gray, R.D. (1993). Can ecological theory predict the distribution of foraging animals? A critical analysis of experiments on the ideal free distribution. - Oikos 68 : 158.

Kilgour, R.J., Norris, D.R. \& McAdam, A.G. (2020). Carry-over effects of resource competition and social environment on aggression. - Behav. Ecol. 31: 140-151.

Knell, R.J. (2009). Population density and the evolution of male aggression. - J. Zool. 278: 83-90.

Kokko, H. \& Sutherland, W.J. (1998). Optimal floating and queuing strategies: consequences for density dependence and habitat loss. - Am. Nat. 152: 354-366.

Kroodsma, D.E., Byers, B.E., Goodale, E., Johnson, S. \& Liu, W.C. (2001). Pseudoreplication in playback experiments, revisited a decade later. — Anim. Behav. 61: 1029-1033.

Lacava, R.V., Brasileiro, L., Maia, R., Oliveira, R.F. \& Macedo, R.H. (2011). Social environment affects testosterone level in captive male blue-black grassquits. - Horm. Behav. 59: 51-55.

Li, C., Jiang, Z., Tang, S. \& Zeng, Y. (2007). Influence of enclosure size and animal density on fecal cortisol concentration and aggression in Père David's deer stags. - Gen. Comp. Endocrinol. 151: 202-209.

López-Sepulcre, A. \& Kokko, H. (2005). Territorial defense, territory size, and population regulation. - Am. Nat. 166: 317-329.

Maclean, A., Huntingford, F.A., Ruxton, G.D., Morgan, I.J., Hamilton, J. \& Armstrong, J.D. (2005). Testing the assumptions of the ideal despotic distribution with an unpredictable food supply: experiments in juvenile salmon. — J. Anim. Ecol. 74: 214-225.

Manenti, R., Pennati, R. \& Ficetola, G.F. (2015). Role of density and resource competition in determining aggressive behaviour in salamanders. — J. Zool. 296: 270-277.

Marra, P.P. (2000). The role of behavioral dominance in structuring patterns of habitat occupancy in a migrant bird during the nonbreeding season. - Behav. Ecol. 11: 299-308.

Maynard Smith, J. \& Brown, R.L.W. (1986). Competition and body size. — Theor. Popul. Biol. 30: 166-179.

Møller, A.P. (1991). Clutch size, nest predation, and distribution of avian unequal competitors in a patchy environment. — Ecology 72: 1336-1349.

Morales, M.B., Casas, F., García de la Morena, E., Ponjoan, A., Calabuig, G., MartínezPadilla, J., García, J.T., Mañosa, S., Viñuela, J. \& Bota, G. (2014). Density dependence and habitat quality modulate the intensity of display territory defence in an exploded lekking species. — Behav. Ecol. Sociobiol. 68: 1493-1504.

Murray, C.M., Mane, S.V. \& Pusey, A.E. (2007). Dominance rank influences female space use in wild chimpanzees, Pan troglodytes: towards an ideal despotic distribution. - Anim. Behav. 74: 1795-1804.

Niemelä, P.T. \& Dingemanse, N.J. (2018a). On the usage of single measurements in behavioural ecology research on individual differences. — Anim. Behav. 145: 99-105.

Niemelä, P.T. \& Dingemanse, N.J. (2018b). Meta-analysis reveals weak associations between intrinsic state and personality. — Proc. Roy. Soc. Lond. B: Biol. Sci. 285: 20172823. DOI:10.1098/rspb.2017.2823. 
Nowicki, S., Searcy, W.A., Krueger, T. \& Hughes, M. (2002). Individual variation in response to simulated territorial challenge among territory-holding song sparrows. - J. Avian Biol. 33: 253-259.

Orians, G.H. (1969). On the evolution of mating systems in birds and mammals. - Am. Nat. 103: 589-603.

Oro, D. (2008). Living in a ghetto within a local population: an empirical example of an ideal despotic distribution. - Ecology 89: 838-846.

Pagán, I., Martínez, J.E. \& Calvo, J.F. (2009). Territorial occupancy and breeding performance in a migratory raptor do not follow ideal despotic distribution patterns. - J. Zool. 279: 36-43.

Peters, S.S., Searcy, W.A. \& Marler, P. (1980). Species song discrimination in choice experiments with territorial male swamp and song sparrows. - Anim. Behav. 28: 393-404.

Pryke, S.R., Lawes, M.J. \& Andersson, S. (2001). Agonistic carotenoid signalling in male red-collared widowbirds: aggression related to the colour signal of both the territory owner and model intruder. - Anim. Behav. 62: 695-704.

Purchase, C.F. \& Hutchings, J.A. (2008). A temporally stable spatial pattern in the spawner density of a freshwater fish: evidence for an ideal despotic distribution. - Can. J. Fish. Aquat. Sci. 65: 382-388.

R Core Team (2013). R: a language and environment for statistical computing. — R Foundation for Statistical Computing, Vienna.

Robinson-Wolrath, S.I. \& Owens, I.P.F. (2003). Large size in an island-dwelling bird: intraspecific competition and the dominance hypothesis. — J. Evol. Biol. 16: 1106-1114.

Scales, J., Hyman, J. \& Hughes, M. (2013). Fortune favours the aggressive: territory quality and behavioural syndromes in song sparrows, Melospiza melodia. - Anim. Behav. 85: 441-451.

Scott, L.M. \& Janikas, M.V. (2010). Spatial statistics in ArcGIS. — In: Handbook of applied spatial analysis (Fischer, M.M. \& Getis, A., eds). Springer, Berlin, p. 27-41.

Seaman, B.D. \& Krementz, D.G. (2000). Movements and survival of Bachman's sparrows in response to prescribed summer burns in South Carolina. - Proc. Annu. Conf. Southeast. Ass. Fish Wildl. Agencies 54: 227-240.

Taillie, P.J., Peterson, M.N. \& Moorman, C.E. (2015). The relative importance of multiscale factors in the distribution of Bachman's sparrow and the implications for ecosystem conservation. - Condor 117: 137-146.

Tregenza, T. (1995). Building on the ideal free distribution. — Adv. Ecol. Res. 26: 253-307.

Tucker, J.W., Robinson, W.D. \& Grand, J.B. (2004). Influence of fire on Bachman's sparrow, an endemic North American songbird. — J. Wildl. Manage. 68: 1114-1123.

Tucker, J.W., Robinson, W.D. \& Grand, J.B. (2006). Breeding productivity of Bachman's sparrows in fire-managed longleaf pine forests. — Wilson J. Ornithol. 118: 131-137.

Tuomainen, U. \& Candolin, U. (2011). Behavioural responses to human-induced environmental change. - Biol. Rev. 86: 640-657.

Vickery, P.D., Hunter, M.L. \& Wells, J.V. (1992). Use of a new reproductive index to evaluate relationship between habitat quality and breeding success. - Auk 109: 697-705. 
Wauters, L.A., Gurnell, J., Preatoni, D. \& Tosi, G. (2008). Effects of spatial variation in food availability on spacing behaviour and demography of Eurasian red squirrels. — Ecography 24: 525-538.

Wingfield, J.C., Ball, G.F., Dufty, A.M., Hegner, R.E. \& Ramenofsky, M. (1987). Testosterone and aggression in birds. - Am. Sci. 75: 602-608.

Winiarski, J.M., Fish, A.C., Moorman, C.E., Carpenter, J.P., DePerno, C.S. \& Schillaci, J.M. (2017a). Nest-site selection and nest survival of Bachman's sparrows in two longleaf pine communities. - Condor 119: 361-374.

Winiarski, J.M., Moorman, C.E. \& Carpenter, J.P. (2017b). Bachman's sparrows at the northern periphery of their range: home range size and microhabitat selection. - J. Field Ornithol. 88: 250-261.

Wolf, L.L. (1977). Species relationships in the avian genus Aimophila. — Ornithol. Monogr.: 23.

Wong, B.B.M. \& Candolin, U. (2015). Behavioral responses to changing environments. Behav. Ecol. 26: 665-673.

Ziadi, P. (2019). Intrasexual selection and the elaboration of a mating signal in the Bachman's sparrow (Peucea aestivalis). M.S. Thesis. Florida Atlantic University, Davie, FL.

\section{Appendix}

\section{Table A1.}

Eigenvalues, variance explained, and correlations of the original variables in the principal components extracted from the variables for body size in male Bachman's sparrows at Jonathan Dickinson State Park in 2018.

\begin{tabular}{lcrr}
\hline Statistics and variables & PC1 & \multicolumn{1}{c}{ PC2 } & PC3 \\
\hline Eigenvalue & 1.583 & 0.810 & 0.607 \\
Percent of variance & 52.772 & 26.993 & 20.234 \\
Cumulative percent & 52.772 & 79.765 & 99.999 \\
Mass (g) & 0.622 & -0.275 & 0.733 \\
Tarsus (mm) & 0.604 & -0.428 & -0.672 \\
Wing chord (mm) & 0.499 & 0.861 & -0.100 \\
\hline
\end{tabular}


Table A2.

Eigenvalues, variance explained, and correlations of the original variables in the principal components extracted from the variables for aggressiveness in male Bachman's sparrows at Jonathan Dickinson State Park in 2018.

\begin{tabular}{lrrrr}
\hline Statistics and variables & PC1 & PC2 & PC3 & PC4 \\
\hline Eigenvalue & 1.834 & 0.949 & 0.790 & 0.427 \\
Percent of variance & 45.851 & 23.718 & 19.753 & 10.677 \\
Cumulative percent & 45.851 & 69.569 & 89.322 & 99.999 \\
Flights & 0.406 & -0.760 & 0.331 & 0.384 \\
Fly-bys & 0.460 & -0.046 & -0.870 & 0.173 \\
Whisper songs & 0.475 & 0.647 & 0.317 & 0.504 \\
Proximity (m) & -0.631 & -0.035 & -0.181 & 0.753 \\
\hline
\end{tabular}

Table A3.

Summary statistics (mean $\pm \mathrm{SD}$ ) for the body size measurements, territory tenure, and reproductive index of male Bachman's sparrows at Jonathan Dickinson State Park in 2018.

\begin{tabular}{lcc}
\hline Variable & Mean & Range \\
\hline Mass $(\mathrm{g})$ & $18.6 \pm 0.1$ & $16.4-20.8$ \\
Tarsus $(\mathrm{mm})$ & $19.5 \pm 0.1$ & $18.3-21.9$ \\
Wing chord (mm) $_{\text {Reproductive index }}{ }^{\mathrm{a}}$ & $58.2 \pm 0.2$ & $56-60$ \\
Territory tenure (year) & $2.3 \pm 0.2$ & $1-4$ \\
\hline
\end{tabular}

${ }^{\mathrm{a}} 1$ = unpaired, 2 = paired but no nesting, $3=$ paired and nesting but no fledglings, $4=$ fledged young; (Winiarski et al., 2017).

Table A4.

Summary statistics (mean $\pm \mathrm{SD}$ ) for the aggression and boldness behaviours of male Bachman's sparrows at Jonathan Dickinson State Park in 2018.

\begin{tabular}{lcc}
\hline Variable & Mean & Range \\
\hline Flights & $1.7 \pm 0.4$ & $0-10$ \\
Fly-bys & $1.9 \pm 0.4$ & $0-8$ \\
Whisper songs & $3.1 \pm 1.3$ & $0-44$ \\
Proximity (m) & $17.6 \pm 0.9$ & $5.1-24$ \\
\hline
\end{tabular}




\section{Table A5.}

Results of the generalized linear and linear models for the relationships between the aggressive behaviours and the body size measurements of Bachman's sparrows at Jonathan Dickinson State Park in 2018.

\begin{tabular}{|c|c|c|c|c|c|c|c|c|c|c|}
\hline \multirow[t]{2}{*}{ Variable } & \multicolumn{2}{|c|}{ Flights } & \multicolumn{2}{|c|}{ Fly-bys } & \multicolumn{2}{|c|}{ Whisper songs } & \multicolumn{2}{|c|}{ Proximity } & \multicolumn{2}{|c|}{ Aggression PC } \\
\hline & $z$ & $p$ & $z$ & $p$ & $z$ & $p$ & $t$ & $p$ & $t$ & $p$ \\
\hline Mass & 1.538 & 0.124 & 0.175 & 0.861 & 7.639 & $<0.001^{*}$ & -1.002 & 0.323 & 1.336 & 0.190 \\
\hline Tarsus & 3.963 & $<0.001^{*}$ & -0.653 & 0.514 & 5.526 & $<0.001^{*}$ & -1.258 & 0.216 & 1.556 & 0.128 \\
\hline Wing chord & 2.735 & $0.006^{*}$ & 3.106 & $0.002^{*}$ & 0.469 & 0.639 & 0.130 & 0.897 & 1.074 & 0.289 \\
\hline Body size PC & 3.799 & $<0.001^{*}$ & 1.145 & 0.252 & 6.424 & $<0.001^{*}$ & -1.040 & 0.305 & 1.872 & 0.069 \\
\hline
\end{tabular}

${ }^{*} p$-values are significant at the 0.05 level or less.

\section{Table A6.}

Summary statistics (mean $\pm \mathrm{SD}$ ) for the territory characteristics of Bachman's sparrow territories at Jonathan Dickinson State Park in 2018.

\begin{tabular}{lcc}
\hline Variable & Mean & Range \\
\hline Territory size (ha) & $1.4 \pm 0.1$ & $0.6-3.9$ \\
Density (sparrows/ha) & $0.4 \pm 0.03$ & $0.2-0.9$ \\
Time since fire (days) & $562.8 \pm 31.7$ & $288-781$ \\
Grass ground cover density (hits) & $8.7 \pm 0.5$ & $2.9-15.2$ \\
Shrub ground cover density (hits) & $0.4 \pm 0.04$ & $0.1-0.8$ \\
Forb ground cover density (hits) & $0.3 \pm 0.05$ & $0.06-1.0$ \\
Grass maximum height $(\mathrm{cm})$ & $35.2 \pm 1.2$ & $21.8-50.8$ \\
Shrub maximum height $(\mathrm{cm})$ & $70.4 \pm 2.5$ & $33.4-110.1$ \\
Forb maximum height $(\mathrm{cm})$ & $21.4 \pm 1.8$ & $6.8-44.3$ \\
Percent vegetation cover $(\%)$ & $51.1 \pm 5.2$ & $0.0-96.9$ \\
Percent litter cover $(\%)$ & $38.6 \pm 4.8$ & $1.0-100.0$ \\
Percent bare cover $(\%)$ & $10.3 \pm 2.0$ & $0.0-38.5$ \\
Percent wetland cover $(\%)$ & $9.2 \pm 1.5$ & $0.0-32.0$ \\
Pine basal area $\left(\mathrm{m}^{2} / \mathrm{ha}\right)$ & $25.9 \pm 1.7$ & $12-48$ \\
\hline
\end{tabular}




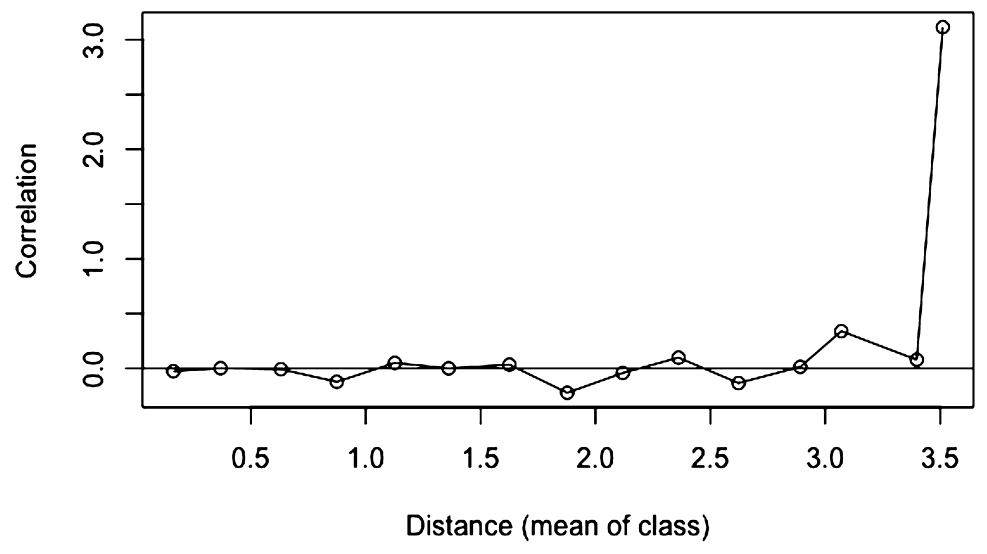

Figure A1. Correlogram of the global spatial autocorrelation (Moran's $I$ ) of the aggressiveness principal component over distance intervals of 0.25 for Bachman's sparrows at Jonathan Dickinson State Park in 2018. 